\title{
Eliciadores proteicos e glicídicos de Adiantum capillus-veneris L. para fitoalexinas em sorgo Sorghum bicolor (L.) Moench
}

\author{
MEINERZ, C.C. ${ }^{* *}$; MULLER, S.F.'; FRANZENER,G. ${ }^{2} ;$ SCHWAN-ESTRADA, K.R.F.2; PORTZ, R.L. ${ }^{;} ;$KUHN, \\ O.J'; STANGARLIN, J.R. ${ }^{1}$ \\ Universidade Estadual do Oeste do Paraná - UNIOESTE, Centro de Ciências Agrárias, Rua Pernambuco 1777, \\ Caixa Postal 91, CEP: 85960-000, Marechal Cândido Rondon-Brasil *crismeinerz@hotmail.com, jrstangarlin@ \\ pq.cnpq.br ${ }^{2}$ Universidade Estadual de Maringá - UEM, Avenida Colombo, 5790, CEP: 87020-900, Maringá- \\ Brasil 3Universidade Paranaense - UNIPAR, Avenida Parigot de Souza, 3636, CEP: 85903-170, Toledo-Brasil
}

\begin{abstract}
RESUMO: Este trabalho objetivou a purificação parcial, por precipitação com sulfato de amônio (SA) e cromatografia de filtração em gel (CFG), de compostos presentes no decocto de Adiantum capillus-veneris (avenca) eficientes na indução de fitoalexinas em mesocótilos de Sorghum bicolor sorgo. Decocto de A. capillus-veneris a 1\% (peso seco/volume) foi precipitado com concentrações de SA variando de 0 a 100\% (em intervalos de $20 \%$ ), e essas frações foram submetidas à CFG. Para o decocto não precipitado foram obtidos nove picos proteicos e um pico glicídico com massas moleculares variando de 0,61 à 0,01 KDa. Para a precipitação fracionada obteve-se: na fração $0-20 \%$ dois picos proteicos (menores que $0,01 \mathrm{KDa}$ ) e dois glicídicos com concentração de açúcares variando de 4,1 a 17,5 $\mu \mathrm{g} \mathrm{mL}-1$; na fração $20-40 \%$ três picos proteicos (111,5 à 0,98 KDa) e cinco glicídicos (11,3 a 73,7 $\mu$ g de açúcares $\mathrm{mL}^{-1}$ ); na fração $40-60 \%$ dois picos proteicos (111,5 à 0,09 $\mathrm{KDa})$ e dois glicídicos $(5,6$ a $7,5 \mu \mathrm{g}$ de açúcares $\mathrm{mL}^{-1}$ ); na fração $60-80 \%$ seis picos proteicos (menores que $0,02 \mathrm{KDa}$ ) e dois glicídicos (16,5 a $51,3 \mu \mathrm{g}$ de açúcares $\mathrm{mL}^{-1}$ ); e na fração $80-100 \%$ três picos proteicos (menores que 0,09 KDa). Mesocótilos de sorgo foram tratados com as frações provenientes da CFG, além do decocto a 1\%, acibenzolar-S-metil (ASM) (125 mg L-1 do i.a. como eliciador de referência) e tampão fosfato de sódio $10 \mathrm{mM} \mathrm{pH} \mathrm{6,0.} \mathrm{O} \mathrm{pico} \mathrm{proteico} \mathrm{II}(0,09 \mathrm{KDa})$ do decocto não precipitado induziu fitoalexinas, $6,68 \%$ superior a ASM. Entre os precipitados, a fração $60-80 \%$ de SA induziu $76 \%$ mais que ASM. Dessa forma, pôde-se obter frações proteicas e/ou glicídicas indutoras de fitoalexinas em sorgo de maneira superior ao extrato (decocto) do qual é originária, indicando o potencial dessas moléculas para trabalhos futuros sobre indução de resistência.
\end{abstract}

Palavras chave: indução de resistência, Adiantum capillus-veneris, deoxiantocianidinas.

ABSTRACT: Proteinaceous and carbohydrate elicitors from Adiantum capillus-veneris inducing phytoalexins in sorghum. This study aimed to partially purify the compounds present in decoction of Adiantum capillus-veneris, which are efficient in the induction of phytoalexins in sorghum mesocotyl, by ammonium sulphate (AS) fractionation and gel filtration chromatography (GFC). The decoction of $A$. capillus-veneris at $1 \%$ (weight/volume) was precipitated with AS at the concentration of $0-20 \%, 20-40 \%, 40-60 \%, 60-80 \%$ and $80-100 \%$, and these fractions were subjected to GFC. For the decoction not precipitated with AS, nine protein peaks and one carbohydrate peak were obtained with molecular weights ranging from 0.61 to $0.01 \mathrm{KDa}$. For the AS precipitation, we obtained: for the fraction $0-20 \%$, two protein peaks $(0.01 \mathrm{KDa})$ and two carbohydrate peaks with concentration of sugars ranging from 4.1 to $17.5 \mu \mathrm{g}$ of sugar $\mathrm{mL}^{-1}$; for the $20-40 \%$, three protein peaks $(0.98$ to $111.5 \mathrm{KDa})$ and five carbohydrate peaks (11.3 to $73.7 \mu \mathrm{g}$ sugar $\left.\mathrm{mL}^{-1}\right)$; for the $40-60 \%$, two protein peaks (0.09 to $111.5 \mathrm{KDa}$ ) and two carbohydrate peaks (5.6 to $7.5 \mu \mathrm{g}$ of sugar $\mathrm{mL}^{-1}$ ); for the $60-80 \%$, six protein peaks (lower than $0.02 \mathrm{KDa}$ ) and two carbohydrate peaks (16.5 to $51.3 \mu \mathrm{g}$ of sugar $\mathrm{mL}^{-1}$ ); and for the $80-100 \%$, three protein peaks with molecular weight equivalent to $0.09 \mathrm{KDa}$. The sorghum mesocotyls were treated with GFC fractions, decoction (1\%), acibenzolar-S-methyl (ASM) (125 mg L-1 a.i. as elicitor reference) and sodium phosphate buffer $(10 \mathrm{mM}, \mathrm{pH} 6.0)$. The protein peak II (0.09 $\mathrm{KDa}$ ) from the decoction not precipitated was effective in inducing phytoalexin, exceeding in 
$6.68 \%$ the ASM. Among the fractions, the one with $60-80 \%$ of AS increased in $76 \%$ the induction of phytoalexin compared to ASM. According to the results, we could obtain protein and/or carbohydrate fractions capable of inducing phytoalexins in sorghum better than the decoction from which they are derived from, showing the potential of these molecules for future research studies on the induction of resistance.

Keywords: induction of resistance, Adiantum capillus-veneris, deoxyanthocyanidins

\section{INTRODUÇÃO}

A indução de resistência consiste na ativação de mecanismos de defesa latentes na própria planta sem qualquer alteração em seu genoma (Romeiro, 2008), esse mecanismo tem sido encarado como forma de controle alternativo de doenças através de plantas em substituição ao uso de pesticidas (Stangarlin et al., 2010). Tal indução é desencadeada por moléculas eliciadoras (ou elicitoras) que podem ser de natureza biótica (como microrganismos viáveis ou inativados ou de origem natural, como os extratos de plantas medicinais) (Stangarlin e Pascholati, 1994; Di Piero e Pascholati, 2004; Silva et al., 2007; Stangarlin et al., 2008) ou abiótica de origem sintética, como ácido aminobutírico, ácido salicílico, ácido jasmônico e acibenzolar-S-metil (Sobrinho et al., 2005).

Uma forma de defesa vegetal induzível é a produção de fitoalexinas, as quais se mostram eficientes em diversas interações plantapatógeno. As fitoalexinas apresentam natureza química variada, são antibióticos com baixa especificidade e seu modo de ação inclui diversos efeitos citológicos que culminam na inibição do crescimento ou morte do patógeno (Braga, 2008). A síntese e o acúmulo de fitoalexinas, assim como ativação de outras respostas de defesa, ocorrem em resposta ao reconhecimento de moléculas eliciadoras (Pascholati e Leite, 1995). Em sorgo são conhecidas quatro fitoalexinas, denominadas flavonóides-3-deoxiantocianidinas (Lo et al., 1996): luteolinidina, apigeninidina, éster do ácido caféico de arabinosil 5-O-apigeninidina e 5-metoxiluteolinidina (Nicholson et al., 1988).

As plantas medicinais possuem compostos secundários que tanto podem ter ação fungitóxica (ação antimicrobiana direta) como eliciadora, ativando mecanismos de defesa nas plantas (ação indireta) (Stangarlin et al., 1999; Schwan-Estrada e Stangarlin, 2005).

A aplicação de extratos brutos de plantas medicinais (Stangarlin et al., 2008) já foi testada quanto a capacidade eliciadora e comprovada para inúmeras interações planta-patógeno, sendo efetivos no controle de várias doenças (Balbi-Penã et al., 2006; Rodrigues et al., 2007; Carvalho et al., 2008; Itako et al., 2009).

A avenca (Adiantum capillus-veneris
L.) é uma planta medicinal perene que possui compostos fenólicos, diversos princípios amargos, tal como a capilarina, e pequena quantidade de óleo essencial (Teske \& Trentini, 1997). A capacidade do extrato aquoso de avenca em causar acúmulo de fitoalexinas em sorgo foi demonstrada por Meinerz et al. (2008), porém ainda não é conhecida a natureza das moléculas eliciadoras.

A purificação parcial de compostos presentes em extratos brutos consiste numa forma prática de obter frações com características indutoras e com potencial para o desenvolvimento de produtos específicos altamente indutores (Moreira et al., 2008). Em ensaios dessa natureza, mesocótilos de sorgo têm sido empregados como modelo de estudo, apresentando metodologia estabelecida e fitoalexinas caracterizadas (Nicholson et al., 1988). Dessa forma, neste trabalho, buscou-se a purificação parcial, por precipitação com sulfato de amônio e cromatografia de filtração em gel, de compostos presentes em folhas de Adiantum capillus-veneris do qual foi retirado o extrato bruto para verificar a capacidade de induzir a produção das fitoalexinas deoxiantocianidinas em mesocótilos de sorgo, buscando selecionar frações potencialmente eficientes para trabalhos futuros na indução de resistência às doenças em plantas.

\section{MATERIAL E MÉTODO}

Obtenção do extrato de $A$. capillus-veneris As folhas de avenca, provenientes do município de Marechal Cândido Rondon/PR, foram coletadas em dezembro de 2009, ao meio dia, devido a maior produção de metabólitos secundários neste horário. As folhas foram secas por 10 dias à temperatura de $25^{\circ} \mathrm{C}$, trituradas em moinho de faca para obtenção de $60 \mathrm{~g}$ do material vegetal, sendo conservadas em local fresco, ao abrigo da luz, conforme metodologia proposta por Teske e Trentini (1997). O extrato aquoso foi obtido por decocção devido a melhor atividade eliciadora de fitoalexinas (Meinerz et al., 2008). Na decocção utilizou-se $1 \mathrm{~g}$ do material vegetal em $100 \mathrm{~mL}$ de água destilada fria à temperatura de $18^{\circ} \mathrm{C}$, aquecendo até a ebulição e

Rev. Bras. PI. Med., Campinas, v.16, n.4, p.794-803, 2014. 
deixando sob aquecimento por 1 min e, em seguida, reservou-se em recipiente fechado por $10 \mathrm{~min}$.

\section{Precipitação fracionada do extrato de avenca com sulfato de amônio}

As proteínas presentes em $100 \mathrm{~mL}$ do decocto de $A$. capillus-veneris foram obtidas a partir de concentrações sucessivas de precipitados com sulfato de amônio em saturações de 0 a $20 \%$, 20 a $40 \%, 40$ a $60 \%, 60$ a $80 \%$ e 80 a $100 \%$ (Di Piero, 2003). O sal foi dissolvido gradativamente, sob agitação, com a solução mantida a $4^{\circ} \mathrm{C}$. Após dissolução do sal a solução foi centrifugada a 20.000 $g$ por 25 min. As proteínas presentes em cada fração foram ressuspensas em $3,5 \mathrm{~mL}$ de tampão fosfato de sódio $0,01 \mathrm{M}(\mathrm{pH} 6,0)$ e efetuada diálise contra água destilada no volume de $4 \mathrm{~L}\left(4^{\circ} \mathrm{C}, 24 \mathrm{~h}\right.$, com três trocas de água). O volume final de cada fração foi ajustado para $10 \mathrm{~mL}$.

Fracionamento do extrato de avenca por cromatografia de filtração em gel (CFG)

Para a cromatografia de filtração em gel, uma coluna de vidro $(1 \mathrm{~cm}$ de diâmetro $\times 30 \mathrm{~cm}$ de comprimento) foi preenchida com Sephacryl S-100HR (Sigma), formando um gel sedimentado de 45,6 $\mathrm{cm}^{3}$. Aplicou-se $1 \mathrm{~mL}$ do decocto e de cada uma de suas precipitações com sulfato de amônio sobre o leito da coluna e eluiu-se com tampão fosfato de sódio $0,01 \mathrm{M}(\mathrm{pH} 6,0)$, sendo coletadas frações de $2 \mathrm{~mL}$ (junção de 6 frações), num fluxo de $1,5 \mathrm{~mL}$ min-1 $^{-1}$ (lurkiv, 2008). Efetuou-se o monitoramento da presença de proteínas das frações obtidas em espectrofotômetro a $280 \mathrm{~nm}$. A presença de carboidratos foi monitorada como descrito por Lever (1972). Cada fração obtida (em um total de até 80 frações) foi testada individualmente para os ensaios de fitoalexinas.

A massa molecular relativa de cada fração detectada foi estimada utilizando-se uma curva de calibração. Para proteína a curva foi construída plotando-se em um gráfico o logaritmo das massas moleculares das proteínas padrão albumina de soro bovino (66 KDa); anidrase carbônica (29 KDa) e bacitracina $(1,45 \mathrm{KDa})$ e o quociente do volume de eluição $(\mathrm{Ve})$ destas proteínas, pelo "void volume" (Vo) (Ve/Vo) (Fiori-Tutida, 2003). A curva padrão de açúcares redutores (glicose) foi obtida pelo método de Lever (1972).

\section{Bioensaio para produção de fitoalexinas em mesocótilo de sorgo}

Sementes de sorgo Sorghum bicolor (L.) Moench, cultivar BRS 610, foram desinfectadas em hipoclorito de sódio a 1\% (15 min), lavadas em água destilada e embebidas em água sob temperatura ambiente por $6 \mathrm{~h}$. Após esse período, foram enroladas em folhas de papel de germinação, umedecidas com água destilada, e incubadas no escuro a $28^{\circ} \mathrm{C}$ por 4 dias. As plântulas formadas foram inicialmente expostas à luz por $4 \mathrm{~h}$ para paralisar a elongação dos mesocótilos (Snyder e Nicholson, 1990).

Para o teste de produção de fitoalexinas, os mesocótilos foram excisados $0,5 \mathrm{~cm}$ acima do nó escutelar e colocados em tubos para microcentrífuga (volume de 1,5 mL), sendo três mesocótilos/tubo, contendo uma alíquota de $1,4 \mathrm{~mL}$ do decocto, de seus precipitados com sulfato de amônio (0-20\%, $20-40 \%, 40-60 \%, 60-80 \%, 80-100 \%$ ), e de suas frações obtidas por CFG. Como padrão utilizou-se água destilada, tampão fosfato de sódio $0,01 \mathrm{M}(\mathrm{pH}$ 6,0 ) e acibenzolar-S-metil (ASM: 125 mg i.a. L-1) (Osswald et al., 2004). Os tubos foram mantidos em câmara úmida, a $25^{\circ} \mathrm{C}$ sob luz fluorescente (Wulff e Pascholati, 1999). Após 60 h, os mesocótilos foram retirados dos tubos, secos, e os $0,5 \mathrm{~cm}$ basais de cada mesocótilo foram cortados e descartados. A porção superior $(2,5 \mathrm{~cm})$ foi pesada, cortada em pequenos segmentos e colocada em tubo para microcentrífuga contendo $1,5 \mathrm{~mL}$ de metanol $80 \%$ acidificado $(0,1 \% \mathrm{HCl} ; \mathrm{v} / \mathrm{v})$. Os mesocótilos cortados foram mantidos a $4^{\circ} \mathrm{C}$ no metanol por 96 h para extração dos pigmentos. A absorbância foi determinada a $480 \mathrm{~nm}$ em espectrofotômetro UV-VIS (Nicholson et al., 1988).

\section{Análise dos resultados}

Os ensaios foram conduzidos em delineamento inteiramente casualizado, com 4 repetições, submetidos à análise de variância e aplicado teste de Scott-Knott $(p \leq 0,05)$ quando pertinente. $O$ programa utilizado para análise estatística foi o software livre Sisvar (Versão 5.0) (Ferreira, 2003).

\section{RESULTADO E DISCUSSÃO}

\section{Purificação parcial por CFG}

Os resultados de purificação parcial do decocto de $A$. capillus-veneris e seus precipitados com sulfato de amônio são apresentados na Figura 1 e Tabela 1. Para o decocto obteve-se nove picos proteicos e um pico glicídico (Figura 1), cujas massas moleculares foram de 0,61; 0,09 e 0,01 KDa para os picos I, II e III respectivamente, e para os demais picos de proteína a massa molecular foi inferior a $0,01 \mathrm{KDa}$. A concentração de açúcar redutor no pico glicídico foi de $57 \mu \mathrm{g} \mathrm{mL}^{-1}$. No precipitado com sulfato de amônio $0-20 \%$ obteve-se dois picos proteicos e dois picos glicídicos, cujas massas moleculares foram menores que $0,01 \mathrm{KDa}$ e a concentração de açúcares redutores foi de 17,5 e $4,1 \mu \mathrm{g} \mathrm{mL}-1$. 

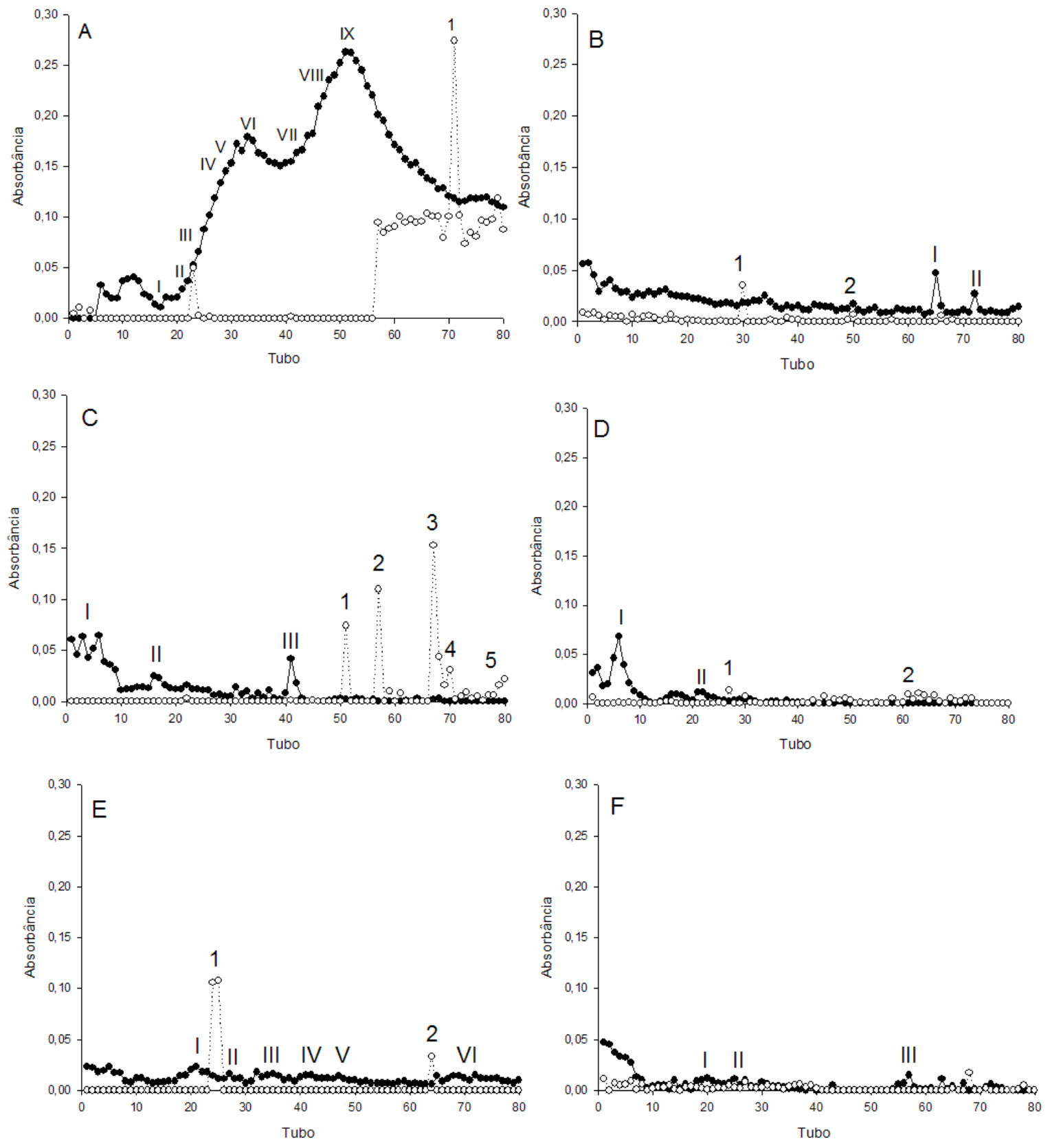

FIGURA 1. Frações proteicas (-๑-: absorbância a $280 \mathrm{~nm}$ ) e glicídicas (-o-: absorbância a $410 \mathrm{~nm}$ ) de decocto de avenca (Adiantum capillus-veneris) a 1\% (A) e de seus precipitados com sulfato de amônio em saturação de 0-20\% (B), $20-40 \%(C), 40-60 \%(D), 60-80 \%(E)$ e $80-100 \%(F)$, obtidos por cromatografia de filtração em gel em coluna de vidro $(1 \mathrm{~cm} \times 30 \mathrm{~cm}$ ) preenchida com Sephacryl S-100-HR (Sigma), e eluido com tampão fosfato de sódio $0,01 \mathrm{M}, \mathrm{pH} 6,0$, sendo coletadas frações de $2 \mathrm{~mL}$, num fluxo de $1,5 \mathrm{~mL} \mathrm{~min}^{-1}$. Os picos referentes às frações proteicas e glicídicas encontram-se numerados sequencialmente com números romanos e arábicos, respectivamente.

No precipitado $20-40 \%$ obteve-se três picos proteicos e cinco picos glicídicos (Figura $1 \mathrm{C}$ ), onde as massas moleculares foram 111,5, 0,98 KDa e < $0,01 \mathrm{KDa}$ para os picos proteicos. Para os picos glicídicos a concentração de açúcares redutores variou de 11,3 a 73,7 $\mathrm{g} \mathrm{mL}^{-1}$ (Tabela 1).

Para o precipitado com saturação de $40-$ $60 \%$ de sulfato de amônio (Figura 1 D) obteve-se dois picos proteicos com massas moleculares de 111,5 a $0,09 \mathrm{KDa}$, e dois picos glicídicos com concentração de açúcares redutores de 5,6 e 7,5 $\mu \mathrm{gL}^{-1}$ (Tabela 1).

No precipitado $60-80 \%$, obteve-se seis picos proteicos com massa molecular menor que $0,02 \mathrm{KDa}$ e dois picos glicídicos, com concentração de açúcar redutor de 51,3 e 16,5 $\mathrm{mg} \mathrm{mL}^{-1}$ (Figura 
1 E). Para o precipitado $80-100 \%$ obteve-se três picos proteicos (Figura 4.1 F), com massa molecular menor que 0,09 KDa (Tabela 1).

$\mathrm{Na}$ literatura não há nenhum relato de trabalho visando à obtenção de fração biologicamente ativa a partir de derivados de avenca. No entanto, a técnica de cromatografia de filtração em gel tem sido utilizada para outros agentes.

Fiori-Tutida (2003), realizando cromatografia de troca iônica seguida de cromatografia de filtração em gel de extratos de dois isolados de Lentinula edodes, obteve 23 picos proteicos para o isolado LE 96/17 e 15 picos para o isolado LE 95/01, comprovando a eficiência do método na purificação dos extratos aquosos de basidiocarpos desse fungo. Para o isolado LE 96/17 as massas moleculares variaram de 0,2 a 75,0 KDa na fração $A$ (I a V); de 1,2 a 75,0 KDa na fração B (I e II); de 1,0 a 78,0 KDa na fração $C$ (I a V); de 0,2 a 72,0 KDa na fração $D$ (I a V); de 1,0 a 66,0 KDa na fração $E$ (I a IV) e de 1,4 a 1,9 KDa na fração F (I e II). Para o isolado LE 95/01 foram obtidos picos com massas moleculares variando de 0,2 a 73,0 KDa na fração $A$ (I a V); de 1,0 a 1,5 KDa na fração B (I e II); de 1,1 a 1,4 KDa na fração $C$ (I e II); de 1,4 a 1,7 KDa na fração $D$ (I e II); de 1,6 a 74,0 KDa na fração $E$ (I e II) e de 1,9 a 80,0 KDa na fração $F(I$ e II).

lurkiv (2008), realizando cromatografia de filtração em gel com extrato bruto do basidiocarpo Pycnoporus sanguineus precipitado com sulfato de amônio, obteve eficiência quanto à purificação parcial por cromatografia de filtração em gel, podendo selecionar quatro frações proteicas, além de uma fração de carboidratos, como potenciais indutores de resistência em soja, cujas massas moleculares variaram de 1,82 a 5,18 KDa.

Di Piero (2003), trabalhando com extrato aquoso de $L$. edodes e cromatografia de troca iônica, obteve seis picos proteicos a partir da aplicação de fração precipitada com saturação de $40-80 \%$ de sulfato de amônia, cujas massas moleculares foram de 29 a $35 \mathrm{KDa}$.

\section{Produção de fitoalexinas em mesocótilos de sorgo}

Os resultados de indução de fitoalexinas para o decocto de A. capillus-veneris e seus precipitados com sulfato de amônio podem ser observados na Tabela 2. O decocto e os precipitados foram semelhantes às testemunhas água destilada e tampão, indicando ausência de indução. Apenas o padrão de indução (ASM) diferiu dos demais tratamentos.

Meinerz et al. (2009), trabalhando com indução de fitoalexinas em sorgo e soja tratados com frações protéicas precipitadas com sulfato de amônia (SA) (0-20; 20-40; 40-60; 60-80 e 80-
$100 \%$ ), a partir de extrato aquoso de Eucalyptus citriodora, verificaram que em sorgo o maior acúmulo de fitoalexinas foi obtido com ASM (seis vezes superior a testemunha), seguido do extrato não autoclavado do precipitado com $40-60 \%$ de SA (3,9 vezes) e extrato autoclavado do precipitado $0-20 \%$ de SA (três vezes). Em soja, a maior indução foi promovida por células de Saccharomyces boulardii que foi duas vezes superior a testemunha, enquanto que os extratos autoclavados e não autoclavados e todas as seis frações foram iguais a testemunha, indicando a ausência de indução de gliceolina por esses materiais.

Di Piero (2003), avaliando o efeito de precipitados obtidos a partir do extrato bruto de basidiocarpos de Lentinula edodes sobre antracnose em plântulas de pepino, verificou que no precipitado obtido com $40-80 \%$ de sulfato de amônio houve um efeito significativo na concentração de açúcares redutores com 141,3 $\mathrm{gg} \mathrm{mL}^{-1}$, na concentração de proteínas, com $3628,4 \mu \mathrm{g} \mathrm{mL}^{-1}$ e no efeito protetor nas plântulas de pepino para controle da antracnose.

A indução de fitoalexinas para as frações obtidas por CFG do decocto e de seus precipitados com sulfato de amônio pode ser observada na Figura 2. Para o decocto (Figura 2A), o elicitor de resistência acibenzolar-S-metil (ASM) não diferiu estatisticamente do tratamento EA $1 \%$, e dos picos proteicos e glicídico pelo teste de Scott-Knott $(P<0,05)$, enquanto o tampão fosfato de sódio foi semelhante aos picos IV, V, VII, VIII e IX e inferiores aos demais picos estudados. O ASM promoveu incremento na produção em relação ao tampão.

$\mathrm{Na}$ Figura 2B são apresentados os dados de indução de fitoalexinas das frações de CFG do precipitado com saturação de sulfato de amônio $0-20 \%$, onde o ASM foi superior ao EA $1 \%$, ao corte 0-20\% (que é o próprio precipitado não submetido à $\mathrm{CFG}$ ) e aos demais picos proteicos e glicídicos, enquanto o tampão não diferiu estatisticamente dos demais.

Para as frações de CFG do precipitado com saturação de sulfato de amônio 20-40\% (Figura 2C) o ASM foi estatisticamente superior ao decocto, ao corte $20-40 \%$ e a todos os picos estudados, enquanto o tampão diferiu somente do pico II. Este promoveu incremento na produção de até 50,6\% em relação ao decocto e ao precipitado $20-40 \%$, indicando assim, a presença de uma fração indutora.

$\mathrm{Na}$ Figura 2D, todos os picos proteicos e glicídicos tiveram atividade menor do que o precipitado com saturação de sulfato de amônio $40-60 \%$, atingindo $79,64 \%$ de redução da produção de fitoalexinas, indicando possivelmente um efeito supressor dos cortes e/ou não recuperação de compostos responsáveis pela indução, em função da separação pela CFG. 
TABELA 1. Massa molecular e concentração de açúcares redutores de frações obtidas por cromatografia de filtração em gel do decocto de Adiantum capillus-veneris e de seus precipitados com sulfato de amônio (SA).

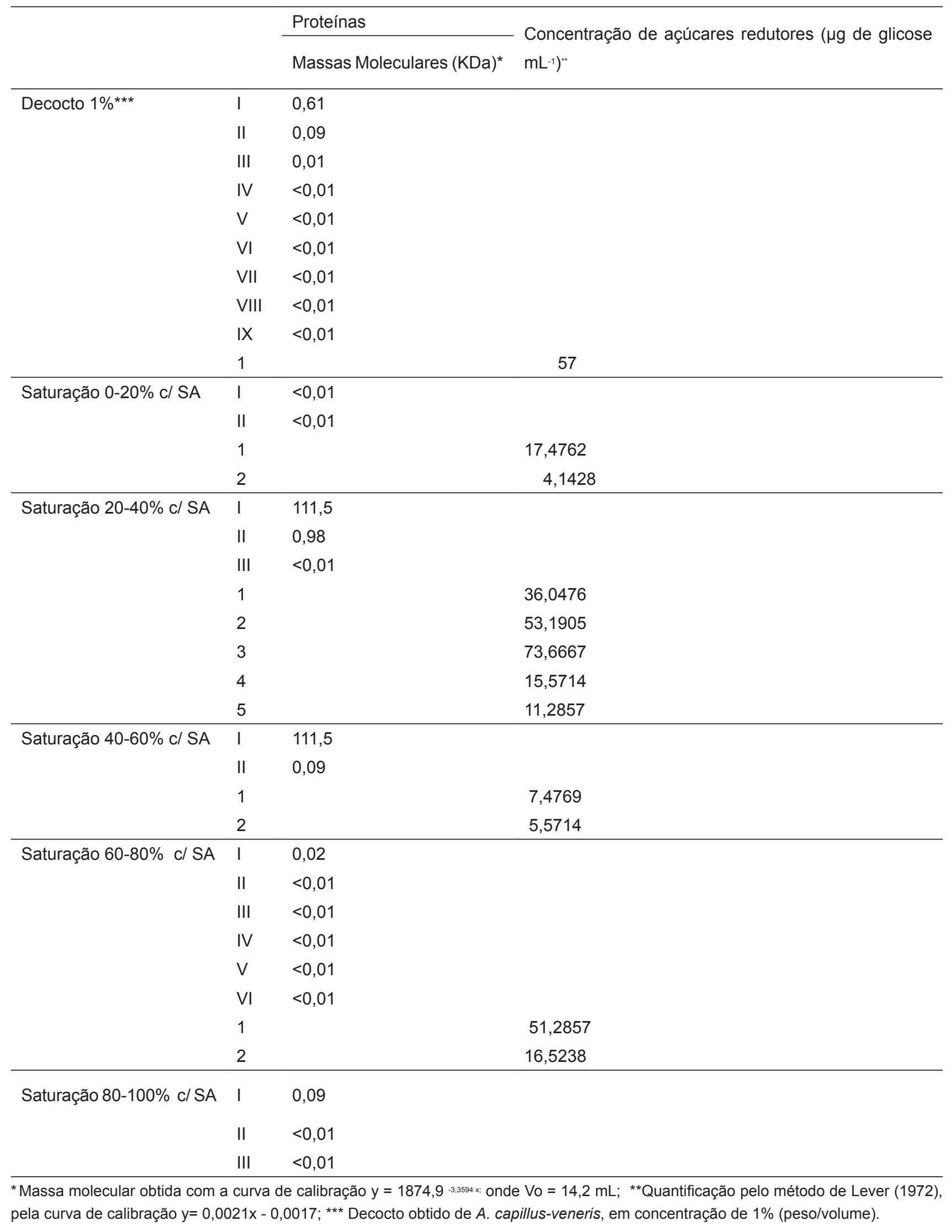

Rev. Bras. PI. Med., Campinas, v.16, n.4, p.794-803, 2014. 
TABELA2. Concentração proteica e de açúcares redutores em frações do decocto de Adiantum capillus-veneris, obtidas na precipitação com sulfato de amônio (SA) e seu efeito na indução de fitoalexinas em mesocótilos de sorgo.

\begin{tabular}{|c|c|c|c|}
\hline Tratamento & $\begin{array}{l}\text { Concentração de } \\
\text { Proteína }\left(\mu \mathrm{g} \mathrm{mL} \mathrm{L}^{-1}\right)^{1}\end{array}$ & $\begin{array}{l}\text { Concentração de açúcares } \\
\text { redutores }\left(\mu \mathrm{gL}^{-1}\right)^{2}\end{array}$ & $\begin{array}{c}\text { Síntese de } \\
\text { Fitoalexinas } \\
\left(\text { Abs. } 480 \mathrm{~nm} \mathrm{gpf}^{-1}\right)^{3}\end{array}$ \\
\hline Decocto $1 \%^{4}$ & 8,152 & 148,904 & $1,0 \mathrm{~b}$ \\
\hline Saturação $0-20 \%$ de SA & 0,129 & 30,809 & $0,60 \mathrm{~b}$ \\
\hline Saturação $20-40 \%$ de SA & 0,183 & 14,619 & $1,20 b$ \\
\hline Saturação $40-60 \%$ de SA & 0,105 & 22,238 & $0,40 \mathrm{~b}$ \\
\hline Saturação $60-80 \%$ de SA & 0,179 & 13,19 & $1,0 \mathrm{~b}$ \\
\hline Saturação $80-100 \%$ de SA & 0,167 & 10,80 & $1,20 \mathrm{~b}$ \\
\hline $\mathrm{ASM}^{5}$ & - & - & $7,80 \mathrm{a}$ \\
\hline $\begin{array}{l}\text { Tampão fosfato de sódio } 0,01 \mathrm{M} \\
\qquad(\mathrm{pH} 6,8)\end{array}$ & - & - & $1,80 \mathrm{~b}$ \\
\hline Água Destilada & - & - & $1,40 \mathrm{~b}$ \\
\hline
\end{tabular}

1 Quantificação pelo método de Bradford (1976), variação de absorbância/ minuto de reação/grama de peso fresco ou por miligrama de proteína; ${ }^{2}$ Quantificação pelo método de Lever (1972); ${ }^{3}$ Quantificação de absorbância por grama de peso fresco. Médias seguidas da mesma letra na coluna não diferem entre si pelo teste de Scott-Knott em nível de $5 \%$ de probabilidade; ${ }^{4}$ Decocto de Adiantum capillusveneris em concentração de $1 \%$ (peso seco/volume); ${ }^{5}$ Acibenzolar-S-metil (125 mg i.a. L-1).

Os precipitados com saturação de sulfato de amônio $60-80 \%$ e $80-100 \%$ mostraram-se superiores ao ASM, tampão fosfato de sódio, EA 1\%, e todos os picos protéicos e glicídicos estudados (Figuras 2 E e F). Entretanto, o corte 60-80\% (Figura $2 \mathrm{E})$ promoveu produção superior ao ASM, com incremento de $75,9 \%$ na atividade indutora.

O método de purificação de eliciadores utilizado tem sido relatado para outros trabalhos. Guzzo e Moraes (1997), buscando a purificação e caracterização parcial de um eliciador de fitoalexinas em soja a partir de urediniósporos de Hemileia vastatrix, obtiveram um eliciador purificado por precipitação etanólica fracionada, seguida por cromatografias de afinidade, troca iônica e exclusão. Os resultados evidenciaram que o eliciador era um polissacarídeo, constituído principalmente por manose $(88,8 \%)$, glicose $(6,7 \%)$ e galactose $(4,5 \%)$. Wulff e Pascholati (1999) utilizam CFG para obter frações purificadas e caracterizar parcialmente um eliciador de fitoalexinas em sorgo a partir de Saccharomyces cerevisiae. Os autores verificaram que os picos II e III tinham proteína e carboidrato e massa molecular aproximada entre 18,4 e $25 \mathrm{KDa}$. Moreira et al. (2008), buscando a purificação e caracterização parcial de um eliciador de fitoalexinas em sorgo e soja por cromatografia de filtração em gel a partir de extratos metanólicos e etanólicos de citronela (Cymbopogon nardus), obtiveram três frações a partir do extrato metanólico (FMI, FMII e FMIII) e duas frações para o extrato etanólico (FEI e FEII), cujas massas moleculares para as frações foram FMI 69,29 KDa; FMII 40,51 KDa; FMIII 18,72 KDa; FEI 65,89 KDa e FEII 24,11 KDa. Quanto ao acúmulo de fitoalexinas em cotilédones de soja não verificaram efeito significativo das frações FMI; FMII; FMIII; FEI e FEII. Entretanto, observaram efeito significativo das frações sobre a produção de fitoalexinas em mesocótilos de sorgo, onde os maiores acúmulos destas fitoalexinas foram promovidas pelas frações FMI e FMIII. Para as fitoalexinas do sorgo, a fração metanólica FMIII foi também a que apresentou a maior produção de fitoalexinas e a fração etanólica FEII a que induziu a menor síntese dessas fitoalexinas.

Outros trabalhos com extratos vegetais utilizados na forma bruta, tem indicado o potencial indutor de fitoalexinas em sorgo. Bonaldo et al. (2007), estudando o efeito do extrato de Eucalyptus citriodora na atividade eliciadora de fitoalexinas em 

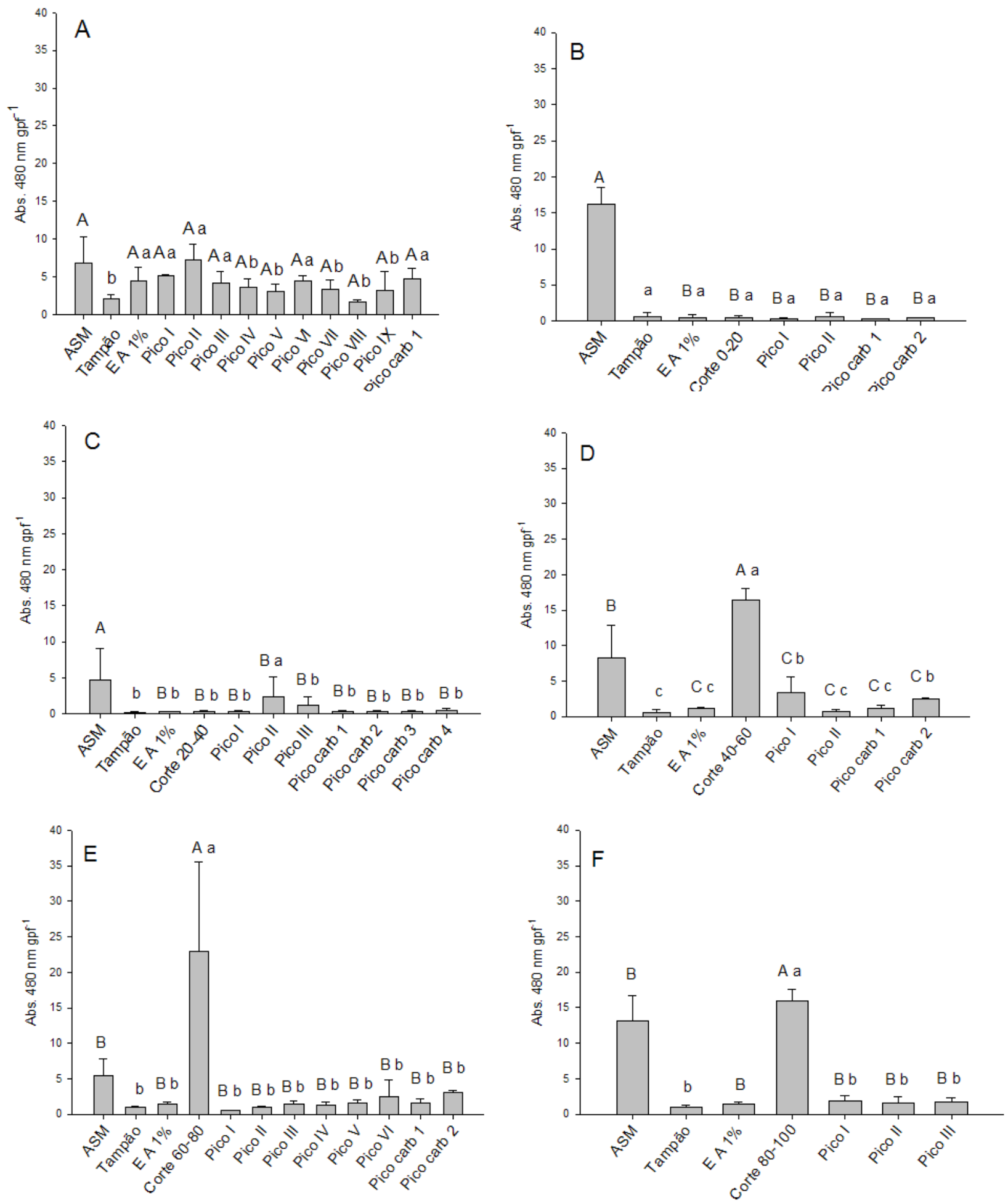

FIGURA 2. Efeito da aplicação de frações parcialmente purificadas de decocto de avenca (Adiantum capillusveneris) $1 \%$ (A) e de seus precipitados com sulfato de amônio em saturação de $0-20 \%$ (B), $20-40 \%$ (C), $40-60 \%$ (D), $60-80 \%$ (E) e $80-100 \%$ (F), obtidos por cromatografia de filtração em gel, na atividade de fitoalexinas em mesocótilos de sorgo. Barras representam o desvio padrão. Médias seguidas de mesma letra maiúscula para comparação com ASM e minúsculas para comparação com tampão não diferem entre si pelo teste de ScottKnott $(p<0,05)$. CV\% $=37,35$. Saturações $0-20 \%$ até $80-100 \%$ representam precipitados protéicos e glicídicos obtidos com diferentes saturações com sulfato de amônia. EA 1\%: decocto de avenca 1\%. Tampão: fosfato 0,01 $\mathrm{M}(\mathrm{pH}$ 6,0). ASM: acibenzolar-S-metil (125 mg L-1 do i.a.). Os picos referentes às frações protéicas e glicídicas encontram-se numerados sequencialmente com números romanos e arábicos, respectivamente. 
sorgo, observaram que esse extrato induziu acúmulo de deoxiantocianidinas.

Schwan-Estrada et al. (1997), utilizando os extratos de orégano (Origanum vulgar), cardo santo (Argemone mexicana), hortelã (Mentha piperita), alecrim (Rosmarinus officinalis), mentrasto (Ageratum conyzoides), babosa (Aloe vera), manjerona (Origanum majorana), erva cidreira (Lippia Alba), cânfora (Artemisia camphorata), pitanga (Stenocalyx michelli), goiabeira (Psidium guayava), romã (Punica granatum), alfavaca (Ocimum basilicum), mil-folhas (Achillea millefolium) e poejo (Mentha pulegium), verificaram que estes extratos promoviam a síntese de fitoalexinas deoxiantocianidinas em sorgo e gliceolina em soja.

Stangarlin et al. (1999) avaliaram a produção de fitoalexinas em mesocótilos de sorgo quando aplicados diferentes extratos de plantas e observaram que extrato de romã (Punica granatum), erva cidreira (Lippia alba), manjerona (Origanum majorana), babosa (Aloe vera) e orégano (Origanum vulgare) foram eficientes na indução de fitoalexinas 3-deoxiantocianidinas em sorgo.

Rodrigues et al. (2007), estudando o efeito do extrato bruto aquoso (EBA) de gengibre (Zingiber officinalis) na atividade eliciadora de fitoalexinas em soja e sorgo, verificaram que o EBA de gengibre, nas diferentes concentrações, apresentou comportamento diferenciado em relação às capacidades de indução de fitoalexinas 3-deoxiantocianidinas e gliceolina, que ocorreu de maneira dose-dependente, indicando que o extrato bruto de gengibre possui a capacidade de ativar mecanismos de defesa nessas plantas.

Vigo (2002) usou tintura vegetal de ginseng brasileiro (Pfaffia glomerata) com seis concentrações $(0,1 ; 1 ; 5 ; 10 ; 20$ e $25 \%)$ para induzir fitoalexinas em mesocótilos de sorgo e observou que houve um aumento na produção desses pigmentos, ficando inferior a este apenas o tratamento com tintura autoclavada a $0,1 \%$. Não houve diferença significativa entre a produção de fitoalexinas com tintura autoclavada e não autoclavada. Dessa forma, constatou que a tintura não perdeu seu poder eliciador quando submetido a altas temperaturas. A autora também observou o aumento gradativo na síntese de fitoalexinas com o incremento nas concentrações de tintura.

Franzener et al. (2003), utilizando extrato de cânfora (Artemisia camphorata) autoclavado e não autoclavado, com e sem incorporação de antioxidante ao extrato, observaram que o estímulo na produção de fitoalexinas foi crescente com o aumento da concentração do extrato vegetal, sendo que os tratamentos não autoclavados apresentaram indução superior aos tratamentos autoclavados. Para o bioensaio de fitoalexinas em sorgo com a incorporação de antioxidante (sulfito de sódio anidro) na concentração de $0,25 \%$, verificou-se que a indução de fitoalexinas foi favorecida com a presença do antioxidante no extrato, indicando que tem potencial de induzir a resistência de plantas a patógenos.

\section{CONCLUSÃO}

Foi possível, através de precipitação com sulfato de amônio e cromatografia de filtração em gel, verificar a presença de picos protéicos e glicídicos com pesos moleculares diferentes para os decoctos não precipitado e precipitado com diferentes concentrações de saturação com sulfato de amônia, purificando parcialmente compostos eliciadores a partir do decocto de $A$. capillusveneris, os quais são capazes de induzir a síntese de deoxiantocianidinas em mesocótilos de sorgo.

\section{AGRADECIMENTO}

Os autores agradecem ao CNPq pelas bolsas de produtividade em pesquisa concedidas a JRS e KRFSE, e a CAPES pela bolsa de mestrado concedida à autora C.C.M.

\section{REFERÊNCIA}

BALBI-PENÃ, M.I.B. et al. Controle de Alternaria solani em tomaterio por extrato de Curcuma longa e curcumina - II. Avaliação in vitro. Fitopatologia Brasileira, Lavras, v. 31, n.4, p. 401-404, 2006.

BONALDO, S.M. et al. Contribuição ao estudo das atividades antifúngicas e elicitoras de fitoalexinas em sorgo e soja por eucalipto (Eucalyptus citriodora). Summa Phytopathologica, Botucatu, v. 33, n. 4, p. 383-387. 2007.

BRADFORD, M. M. A rapid and sensitive method for the quantitation of microgram quantities of protein utilizing the principle of protein-dye binding. Analytical Biochemistry, v. 72, p. 248-254, 1976.

BRAGA, M.R. Fitoalexinas. In: PASCHOLATI, S.F.; LEITE,B.; STANGARLIN, J.R.; CIA, P. Interação plantapatógeno: fisiologia, bioquímica e biologia molecular. Piracicaba-SP. Ed. FEALQ. v 13. 2008, p. 305-346.

CARVALHO, J.B. et al. Fungitoxicidade de Cymbopogon citratus e Cymbopogon martinii a Colletotrichum gloesporioides em frutos de pimentão. Revista Brasileira de Plantas Medicinais, Botucatu, v. 10, n.1, p. 88-93, 2008.

DI PIERO, R.M. Potencial dos cogumelos Lentinula edodes (Shiitake) e Agaricus blazei (cogumelo-dosol) no controle de doenças em plantas de pepino, maracujá e tomate, e a purificação parcial dos compostos biologicamente ativos. 2003. 157p. Tese (Doutorado em Agronomia). ESALQ - Escola Superior de Agricultura "Luiz de Queiroz", Universidade de São Paulo. Piracicaba. 
DI PIERO, R.M.; PASCHOLATI, S.F. Efeito dos cogumelos Lentinula edodes e Agaricus blazei na interação entre plantas de tomate e Xanthomonas vesicatoria. Summa Phytopathologica, Botucatu, v. 30, p. 57-62. 2004.

FERREIRA, D.F. Sisvar. Sistema de análises estatísticas. Lavras, UFLA, 2003.

FIORI-TUTIDA, A.C.G. Uso de extratos dos cogumelos Lentinula edodes (Berk.) Pegler e Agaricus blazei (Murril) ss. Heinem no controle in vitro de Puccinia recondita f. sp. tritici e na indução de resistência em trigo à Bipolaris sorokiniana. 2003. 112p. Tese (Doutorado em Agronomia). Maringá PR. UEM Universidade Estadual de Maringá.

FRANZENER, G. et al. Atividade antifúngica e indução de resistência em trigo a Bipolaris sorokiniana por Artemisia camphorata. Acta Scientiarum, Maringá, v. 25, n. 2, p. 503-507, 2003.

GUZZO, S.D.; MORAES, W.B.C. Purificação e caracterização parcial de um elicitor de fitoalexina em soja, a partir de urediniósporos de Hemileia vastatrix. Fitopatologia Brasileira, Brasília, v.22, n.3. 1997.

ITAKO, A.T. et al. Controle de Cladosporium fulvum em tomateiro por extratos de plantas medicinais. Arquivos do Instituto Biológico, São Paulo, v. 76, n. 1, p. 75-83, 2009.

IURKIV, L. Purificação parcial de compostos biologicamente ativos a partir de Pycnoporus sanguineus para o controle de ferrugem asiática em soja. 2008. 118p. Dissertação (Mestrado em Agronomia). Marechal Cândido Rondon PR. UNIOESTE - Universidade Estadual do Oeste do Paraná.

LEVER, M. A new reaction for colorimetric determination of carbohydrates. Analytical Biochemistry, v. 47, p. 273-279. 1972.

LO et al. Phytoalexin accumulation in sorghum: identification of a methyl ether of luteolinidin. Physiological and Molecular Plant Pathology, London, v. 49, p. 21-31. 1996.

MEINERZ, C.C. et al. Atividade elicitora de fitoalexinas em sorgo e soja por derivados de avenca (Adiantum capillusveneris L.). Revista Brasileira de Plantas Medicinais. Botucatu, v.10, n.2, p.26-31. 2008.

MEINERZ, C.C. et al. Atividade de fitoalexinas em sorgo e soja tratados com frações obtidas de Eucalyptus citriodora. Tropical Plant Pathology (Suplemento), Lavras, v. 34, p. 46-46. 2009.

MOREIRA, C.G.A. et al. Caracterização e purificação parcial de frações obtidas de extrato de Cymbopodon nardus com atividade elicitora de fitoalexinas em sorgo e soja e efeito sobre Colletootrichum lagenarium. Summa Phytopathologica, Botucatu, v. 34, n. 4, p. 332-337. 2008.

NICHOLSON, R.L. et al. Phytoalexin synthesis in the juvenile sorghum leaf. Physiological and Molecular Plant Pathology, London, v. 33, n.2, p.271-278, 1988.

OSSWALD, W.F. et al. The effect os acibenzolar-S-methyl on phytoalexin and PR-protein induction on sorghum mesocotyls and on Colletotrichum sublineolum. Summa Phytopathologica, Botucatu, v. 30, n. 4, p. 415-420. 2004.

PASCHOLATI, S.F.; LEITE,B. Mecanismos de Resistência. In: BERGAMIN FILHO, A.; KIMATI, H.; AMORIM, L. Manual de Fitopatologia - Princípios e Conceitos. São Paulo: Ceres, 1995. cap. 22, 1995. p. 417- 453.
RODRIGUES, E.R. et al. Fungitoxicidade, atividade elicitora de fitoalexinas e proteção de alface em sistema de cultivo orgânico contra Sclerotinia sclerotiorum pelo extrato de gengibre. Summa Phytopathologica, Botucatu, v. 33, n. 2, p. $124-128.2007$

ROMEIRO, R.S. Indução de resistência em plantas a patógenos. In: PASCHOLATI, S.F.; LEITE, B.; STANGARLIN, J.R.; CIA, P. (Eds.) Interação plantapatógeno: fisiologia, bioquímica e biologia molecular. Piracicaba: FEALQ. 2008. p.411-431.

SCHWAN-ESTRADA, K.R.F. et al. Efeito do extrato bruto de plantas medicinais na indução de fitoalexinas em soja e sorgo. Fitopatologia Brasileira, Brasília, v. 22, (Suplemento), p. 346-346. 1997.

SCHWAN-ESTRADA, K.R.F.; STANGARLIN, J.R. Extratos e óleos essenciais de plantas medicinais na indução de resistência. In: CAVALCANTI, L.S.; DI PIERO, R.M.; CIA, P.; PASCHOLATI, S.F.; RESENDE, M.L.; ROMERO, R.S. Indução de resistência em plantas a patógenos e insetos. Piraciacaba: FEALQ,. 2005. p.125-138.

SILVA, R.F.; PASCHOLATI, S.F.; BEDENDO, I.P. Indução de resistência em tomateiro por extratos aquosos de Lentinula edodes e Agaricus blazei contra Ralstonia solanacearum. Fitopatologia Brasileira, Lavras, v. 32, p.189-196. 2007.

SNYDER, B.A.; NICHOLSON, R.N. Systhesis of phytoalexin in sorghum as a site-specific resonses to fungal ingress. Science, v. 3, p. 86-90. 1990.

SOBRINHO, C.A. FERREIRA, P.T.O.; CAVALCANTI, L.S. Indutores abióticos. In: CAVALCANTI, L.S.; DI PIERO, R.M.; CIA, P.; PASCHOLATI, S.F.; RESENDE, M.L.V.; ROMEIRO, R.S. Indução de resistência em plantas a patógenos e insetos. Piracicaba: FEALQ, 2005. p. 51-80.

STANGARLIN, J.R.; PASCHOLATI, S.F. Proteção de plântulas de milho pipoca contra Exserohilum turcicum pelo uso de Saccharomyces cerevisiae. Summa Phytopathologica, Jaboticabal, v. 20, p. 16-21, 1994.

STANGARLIN, J.R. et al. Indução de fitoalexinas em soja e sorgo por preparações de Saccharomyces boulardii. Arquivos do Instituto Biológico, São Paulo, v. 27, n. 1, p. 91-98, 2010

STANGARLIN, J.R. et al. Plantas medicinais e controle alternativo de fitopatógenos. Biotecnologia, Ciência e Desenvolvimento. Brasília, v.11, p.16-21. 1999.

STANGARLIN, J.R.; KUHN, O.J.; SCHWAN-ESTRADA, K.R.F. Controle de doenças de plantas por extratos de origem vegetal. Revisão Anual de Patologia de Plantas. Passo Fundo, p.265-304. 2008.

TESKE, M.; TRENTINI, A.M. Compêndio de fitoterapia. 3. ed. Curitiba: Ed. Herbarium Laboratório Botânico, 1997. 317p.

VIGO, S.C. Controle de Microsphaera diffusa (oídio da soja) pelo uso da tintura vegetal da planta medicinal Pfaffia glomerata (Ginseng Brasileiro). 2002. p. 29. Trabalho de Conclusão de Curso em Agronomia. Marechal Cândido Rondon PR. UNIOESTE - Universidade Estadual do Oeste do Paraná.

WULFF, N.A.; PASCHOLATI, S.F. Caracterização parcial de elicitores de fitoalexinas em sorgo isolados de Saccharomyces cerevisiae. Fitopatologia Brasileira, Brasília, v. 24, n. 3, p. 428-435, 1999. 